This item was submitted to Loughborough's Research Repository by the author.

Items in Figshare are protected by copyright, with all rights reserved, unless otherwise indicated.

\title{
The minimum income standard as a benchmark of a 'participatory social minimum'
}

\section{PLEASE CITE THE PUBLISHED VERSION}

https://doi.org/10.1332/175982717X15087736009278

\section{PUBLISHER}

(C) Policy Press

\section{VERSION}

AM (Accepted Manuscript)

\section{PUBLISHER STATEMENT}

This work is made available according to the conditions of the Creative Commons Attribution-NonCommercialNoDerivatives 4.0 International (CC BY-NC-ND 4.0) licence. Full details of this licence are available at: https://creativecommons.org/licenses/by-nc-nd/4.0/

\section{LICENCE}

CC BY-NC-ND 4.0

\section{REPOSITORY RECORD}

Davis, Abigail, Donald Hirsch, and Matt Padley. 2017. "The Minimum Income Standard as a Benchmark of a 'participatory Social Minimum"'. Loughborough University. https://hdl.handle.net/2134/26704. 


\title{
The minimum income standard as a benchmark of a 'participatory social minimum'
}

Abigail Davis, a.a.i.davis@lboro.ac.uk, Donald Hirsch, donald.hirsch@googlemail.com and Matt Padley, m.j.Padley@lboro.ac.uk, Loughborough University UK

\begin{abstract}
The Minimum Income Standard (MIS), a method for constructing minimum household budgets based on public consensus, helps to operationalise Townsend's concept of a 'participatory social minimum'. Since 2008 MIS has tracked changes in the contents and cost of minimum baskets of goods and services. The article reflects on aspects of this research: the living standard that MIS represents, how consensus is reached and its record of providing consistent results over time. Understanding these features allows policy makers, practitioners and analysts to use the results of MIS appropriately, alongside other research, to benchmark the success of measures to promote adequate incomes.
\end{abstract}

\section{Acknowledgements}

We would like to thank the Joseph Rowntree Foundation for their continuing support of this research, and the members of the public who have participated in this work with such energy and enthusiasm. We would also like to thank the Journal's reviewers and editors, as well as colleagues at Loughborough University and elsewhere for their helpful comments and suggestions. 


\section{Introduction}

There is today widespread political and public agreement over the need to help groups who have been 'left behind' by economic growth and prosperity. This is not however matched by a clear, commonly shared understanding of how to judge progress in helping households on low incomes to attain acceptable living standards. While poverty and living standards are multi-dimensional, public policies affecting household income have to take a view of what levels of income are likely to meet people's needs (Spicker, 2012).

Modern concepts of poverty and minimum living standards go beyond describing the income threshold required to meet the basic material essentials of subsistence, typified by Rowntree's (1901) measurement of 'primary poverty'. In the late $20^{\text {th }}$ century, writers such as Townsend (1979) and Doyal and Gough (1991) emphasised the importance of meeting psychological and emotional as well as physical needs. Townsend made social criteria central by defining people as being in poverty if they lack the resources necessary to reach a living standard considered 'customary, or at least widely encouraged or approved in the societies to which they belong' (1979: 31).

In designing policies to promote incomes compatible with social inclusion, governments can draw on various indicators and thresholds, each with advantages and limitations. Indicators of relative poverty, such as those central to the UK government-produced Households Below Average Income series (DWP, 2017), track the number of households falling well below an income norm, based on the idea that relative economic welfare is important 'economic distance'. But relative income indicators alone do not account for the extent to which low income lowers people's 'capabilities' and prevents them from functioning in society (Ravaillon and Chen, 2011: 1252; Sen, 1985; Hick, 2012). Deprivation measures yield more direct evidence of the negative consequences of low income, using surveys to show how many households are unable to afford items considered to be necessary by a majority of members of the public (Mack and Lansley, 1985; Gordon and Pantazis, 1997; Gordon et al, 2001, 2013; Fahmy, 2014). These provide a broad indication of trends in the numbers who are deprived in this sense, but do not in themselves tell 
policy makers what income level a household requires to meet its needs. Income levels have clear correlations with the risk of deprivation, with good health and poor health, and social survey data can be used to shed light on the extent of these risks (Deeming, 2017). However, the evidence tends to show a continuous gradient, rather than a clear-cut income threshold at which these risks rapidly become more likely (Berthoud and Bryan, 2011; Hirsch et al, 2016: 20; Marmot, 2010).

While both deprivation and relative income provide useful tools in monitoring low income and its consequences, neither is directly referenced on evidence of how much income households actually need to maintain a participatory social minimum. A third strand of research, focused on establishing budget standards, can complement these other indicators by identifying such an income as a benchmark or reference-point. Budget standards identify income thresholds sufficient to purchase a set of items required to meet household needs (Bradshaw, 1993, Davis et al, 2015). As discussed later in this article, central to budget standards approaches then are critical questions of how such standards are calculated, by whom, and against what definition of need. These characteristics of budget standards research influence how they should be interpreted and used by policy makers and others.

This article describes the development and calculation of one form of budget standard, the Minimum Income Standard (MIS), in recent years. This takes the form of a 'consensual' budget standard, that is one based on what members of the public judge to be enough for people to reach a 'minimum standard of living'. Such a measure was first proposed by Walker (1987), and developed by Middleton (2000) before being applied using the current method from 2008 (Bradshaw et al, 2008). Walker's view was that Townsend's 'participatory social minimum' was best operationalised by building consensus among citizens about what it means and takes to participate fully in society. A consensual standard as proposed by Walker and later implemented in MIS seeks to represent not a 'poverty line', but rather a more positive concept of a decent living standard in the eyes of citizens. Its placing of members of the public at the centre of decision-making distinguishes it from other budget standards research based more on expert judgements in conjunction with expenditure and other data (Bradshaw, 1993; Deeming, 2010; Storms et al, 2013). 
The Minimum Income Standard research has provided a regularly updated set of annual income benchmarks for a range of households since 2008 . The main purpose of this article is to describe and reflect on critical aspects of this research, in order to shed light on how its results can be interpreted and used by policy makers, practitioners and analysts. Specifically, the remainder of the article considers: first, the research design and the criteria used to identify what households need; second, how the central feature of formulating a social consensus has worked in practice; and third, the record of the research in providing data of sufficient consistency to be useful as a way of monitoring progress in reducing low income. The conclusion reflects on how the evidence that the Minimum Income Standard produces can inform policy makers, practitioners and analysts.

\section{The MIS research, how it defines adequacy and who decides}

The Minimum Income Standard research entails members of the public drawing up lists of items that a range of different households require. The lists are principally drawn up through a series of deliberative focus groups, and successive groups build up budget lists through negotiation and consensus. The method is not an opinion poll of individuals, nor does it seek to average the views of different groups, but is rather a mediated set of negotiations whose results have been built up through multiple interactions: between individuals within groups, between different groups and between members of the public and experts (for more detail see Bradshaw et al, 2008 and Davis et al, 2015). Supported by the Joseph Rowntree Foundation, the MIS research for the whole UK has been carried out regularly since 2008.

In considering both the meaning of the standard and the methods used to calculate it, it is useful to consider four conceptual criteria set out by Veit Wilson (1998: 21) with regard to what income is adequate: 'adequacy for what? adequacy for how long?, adequacy for whom? and who says?' (italics in original). The first two questions influence the design of the research stages of MIS and of the guides used by researchers to initiate, mediate and structure the discussion. The latter two inform recruitment processes and group composition. 


\section{Adequacy for what?}

Previous budget standards research has adopted various approaches to defining an 'adequacy' level, in terms of what level of needs or living standards it seeks to represent. For example, the University of York's Family Budget Unit defined two levels as (i) 'modest but adequate', interpreted as 'the standard at which most households aim: roughly twice the poverty threshold but well short of affluence' and (ii) 'low cost but acceptable', described as equating to the poverty line (Parker, 2002). In devising a common basis for reference budgets in various European countries, Storms et al (2013) draw on a theoretical framework anchored in a theory of human need (Doyal and Gough, 1991).

The Minimum Income Standard research started with a broad concept of what households require for a minimum standard of living, but no further predefinition of what this should mean. Rather, the initial study in 2006-2008 started with an exploratory phase of eight 'orientation' groups, who discussed what a minimum standard of living in Britain today should include or exclude in broad 'categorical', rather than specific terms. In addition to basic requirements such as food, clothing and accommodation compatible with good health, other, less material aspects were emphasised, such as the need for educational and employment opportunities, security, and the ability to maintain relationships with friends and family.

The discussions were analysed thematically and used to formulate a statement intended to express what constitutes adequacy in today's society:

A minimum standard of living in the UK today includes, but is more than, just food, clothes and shelter. It is about having what you need in order to have the opportunities and choices necessary to participate in society. (Davis et al., 2016: 1).

This definition underlying MIS has been used in all subsequent groups throughout the research programme. This consistent framing strengthens the probability that groups have a shared idea of the living standard that a minimum income is intended to provide and around which consensus can be built. By articulating the requirement for opportunities, choices and participation, it goes beyond a narrow concept of 
escaping poverty by avoiding hardship. This aligns with previous formulations of social inclusion as a need - going back to Adam Smith's (1776) judgement that you need a linen shirt to be respectable; including the radical J.A. Hobson's (1891) recognition that necessities go beyond subsistence and also have a social dimension; and later at the heart of Townsend's (1979) concept of adhering to social custom, referred to earlier. Importantly, the reference in the MIS definition to need distinguishes it from the 'modest but adequate' standard's reference to what people 'aim' at: MIS groups always distinguish between 'needs' and 'wants' when considering what to include in minimum budgets.

\section{Adequacy for how long?}

It is possible to design budget standards that are designed to be suitable for only a brief period - for example while people are on a reduced income when out of work, based on the assumption that they will be unemployed for a limited time and then will have a higher income that allows a higher standard of living. However, there is much evidence to support the claim that living at a subsistence level for a prolonged period can have damaging consequences. Low income often forces people to prioritise their resources, leaving some needs unmet, including postponing or going without routine health or dental care, cutting back on food and feeling constrained in their ability to socialise or feel included, which can have adverse effects on their selfesteem and emotional health (e.g. Daly and Kelly, 2015; Hill et al, 2016; Kempson, 1996; Kyprianou, 2015). MIS seeks to establish a level at which a household could live for an indefinite period without this causing its mellmbers negative consequences in terms of their physical, mental or emotional well-being, and includes spending on replacing household goods and other longer-lasting items, translating these expenses into pro rata weekly amounts according to their expected lifetime.

\section{Adequacy for whom? and Who says?}

Walker suggested in 1987 that budget standards should be grounded in experiential knowledge and public consensus. But this raises the critical question of whose experiences should be taken into account, and who should agree on what comprises essentials. One approach is for people on low incomes to draw on their experiences to identify what people on low incomes need; another is for people from across 
income groups to discuss what comprises a minimum in the context of how people live more generally.

Previous studies have adopted a variety of different approaches to this. Research in New Zealand (Waldegrave et al, 1996), Canada (Winnipeg Harvest and the Social Planning Council of Winnipeg, 2012) and Belgium (Storms, 2000) for example, involved participants drawn exclusively from low income households, based on the idea that they would be best placed to understand what a modest standard of living should include. However, Middleton (2000) argued that gathering opinions only from those already in potentially financially constrained circumstances would be more likely to generate a description of life on a low income, rather than a broader societal consensus of what is needed by any citizen in order to have a minimum socially acceptable standard of living. Deeming (2017), building on Bourdieu's (1984) analysis of taste and class, similarly demonstrates that such socially selective research will bias findings to cater for only certain social classes and consequently tastes (Atkinson and Deeming 2015). The MIS research conducted in the UK therefore recruits participants from across a range of different socio-economic groups. It asks them to consider what a hypothetical 'case study' individual or household would require as a minimum, without specifying their income or socioeconomic status, in order not to prejudice discussions about what people need with assumptions about what their economic situation enables them to afford.

Each wave of groups in MIS is recruited afresh in order to avoid results depending excessively on the perspectives of any one group of individuals. By recruiting from the same demographic as the individual or household whose needs are being discussed, MIS ensures that participants are informed by their own experiences, and are able to explain why certain items are needed or not needed, situating decisions in everyday life. For instance, when discussing whether internet access is a necessity in the home, rather than via public facilities such as libraries, parents with pre-school children cited practical difficulties in using a computer with a young child in tow, while those with school-age children noted the limitations of doing homework only during library opening hours. 
While the central principle of MIS is therefore that decisions about necessities rest with members of the public who have the greatest 'expertise' in what it is like to live in a particular household type in contemporary society, there are some areas where this everyday knowledge is supplemented by technical knowledge. For example, after groups specify the minimum size of house or flat required, a domestic fuel expert estimates the energy required to heat and power such a home, compatible with keeping it sufficiently warm: this requires technical knowledge not held by most members of the public. In the case of food, lay and expert knowledge interact, with members of the public having the final say. A nutritionist uses descriptions of typical meals drawn up by groups for a range of different individuals, combining these into weekly menus. These are then analysed against nutritional guidelines recommended for maintaining health (e.g. the Recommended Daily Intake (RDI) of vitamins and minerals, the amount of saturated vs unsaturated fat, calorie intake and so forth). If the nutritionist finds that the guidelines would be better met with the addition or reduction of some components any suggested changes are taken back to groups to check that this is acceptable.

\section{$3 \quad$ Formulating a consensus}

A central challenge for the MIS method is to identify items required for a minimum living standard based on consensus among members of the public. The advantage of focus groups over individual interviews in social research is that the interaction between participants helps to formulate perspectives that may not have been yielded from the isolated questioning of individuals (Merton and Kendall, 1946; Krueger and Casey, 2009;). However, deliberative focus groups seek to go further, not just revealing fresh perspectives but being tasked with taking decisions through 'consensus' - interpreted as meaning 'general agreement', rather than 'unanimity' (Urfalino, 2006; Moore, 2012; Smithson and Diaz, 1996, Deeming, 2017).

Sometimes individuals start by expressing different individual views, and group discussion seeks to reach a decision acceptable to the group as a whole. This may involve negotiating a common position, with the possibility of some individuals acknowledging that their own personal views are outliers. Another approach, used by Fahmy et al (2012) to identify necessities through focus groups as part of the UK Poverty and Social Exclusion Survey, is to take a majority view where agreement 
cannot be reached. This is not the approach used within MIS, which rather seeks to build a consensus over a sequence of groups: where a single group does not reach agreement, subsequent groups take account of the earlier group's arguments in reaching decisions (see below).

This consensus-building process can be understood first in terms of its purpose in relation to identifying a social minimum, second in terms of the research process and third in terms of how it has been worked out in the MIS research.

\section{Collective objectivity rather than individual subjectivity}

Walker (1987: 213-214) pointed to a crucial weakness of using survey questions in order to find out what people think are 'necessities': respondents are being 'asked to provide immediate responses to tightly worded questions about complex and sensitive issues to which few of them will previously have given much thought'. Moreover, in giving an initial opinion on what comprise 'needs', it seems reasonable to assume that each person will be responding as an individual, strongly based on their own individual experiences and preferences, even if the question invites them to consider what is needed more generally by others in society. Since research on socially defined necessities seeks to consider what society in general deems essential for everyone, such an individualised research method has serious limitations. Burchardt (2014: 15) suggests instead that adopting a deliberative approach is 'particularly well-suited to situations where the challenge is to identify an informed, considered, and collective view.'

In MIS groups, the task is carefully and consistently framed in order to do all that is possible to avoid individuals simply expressing their own personal views in isolation. The emphasis is on the group developing a collective view, in which participants are informed by the perspectives of others. Reference to the needs of hypothetical 'case study' individuals helps with this projection away from one's own preferences, towards a more generalised conception of what people need. While participants draw upon their own experiences and knowledge of the world around them, they are encouraged to adopt an objective stance in considering with fellow-participants, why someone might need various items in order to reach a minimum socially acceptable standard in keeping with the MIS definition referred to previously. 


\section{Methods for dealing with difference}

A critical aspect of consensus building is how differences are dealt with. In many cases, participants start with common or similar views of what items are needed for an acceptable standard of living. In instances where participants initially express differing views, detailed discussion and negotiation commonly allows them to converge on answers that the group as a whole can agree on. The facilitator's role is to ensure that different views are heard, and to moderate the discussion and move it along; referring groups back to the MIS definition and the case study where necessary, capturing decisions, reflecting key points back to the group, and probing for rationales.

In carrying out these tasks it is important for the researchers to seek to minimise the well documented potential disadvantages of focus groups, including researcher bias and the unequal weight given to "louder and quieter voices" (Deeming, 2017; Morgan, 1997). While these risks cannot be fully eliminated, the research always uses two researchers who jointly analyse the decisions reached, helped by transcribed recordings, and by flipcharts used within the group recording decisions in real time. The latter feature allows facilitators to check explicitly with the group that decisions have been interpreted correctly, giving individuals the chance to object where this is not the case.

A further key feature of the MIS research is its approach to developing a negotiated consensus in successive groups. New participants are recruited at each stage in a different location. After the first wave of groups, researchers compile lists of items based on group decisions to take to subsequent groups, who review not only what items are included but also the specified quantity, quality, lifespan and retailer. There is a large level of agreement in between stages, as well as some instances of revision of the detail of budgets, where a later group brings some new points into consideration having been informed of and taken account of the earlier group's reasoning. In addition, in the small minority of cases where groups have not been able to reach consensus, subsequent groups are tasked with resolving differences. In these instances it is useful to be able to present any conflicting points of view to a new group of people, who have not become entrenched in particular positions and 
are thus more able to consider the arguments 'dispassionately' than the previous group.

\section{Reaching consensus in practice}

Davis et al, (2015) provide an account with detailed illustrations of how consensus is reached within MIS. While many decisions are made relatively quickly and directly without controversy, others can be the subject of lengthy and detailed debate before reaching a conclusion. For example, when discussing whether a family with children need a tumble drier, some parents start by viewing this this as a luxury (a 'nice to have' rather than 'need to have' item), suggesting that washing can be dried on an outside clothes lines and on airers inside the home, while others say this is not be sufficient. One reason why negotiation has been effective for this item is that rather than being asked to decide whether or not a tumble drier is either always or never essential for a family, parents debate what family size represents a 'tipping point' above which this becomes a necessity. Groups of parents have consistently agreed that if there are one or two children in a family a tumble dryer is not essential, but if there are three or more, then this is needed in order to be able to get clothing, bedding and towels dry.

Not all decisions are dichotomous: some centre more around the nature of an item than whether it should be included or not. For example, groups are unanimous that a home needs comfortable seating, but take time to deliberate over whether, to meet this need, a sofa should be fabric or leather, and what the implications are of each decision in terms of value for money and durability. Parents have discussed the fact that leather furniture is easier to wipe clean, and more likely to be hard wearing, but have ultimately agreed that a fabric three piece suite with washable covers would last as long, if a blanket or throw is put over it to reduce wear and tear. In this case, discussion strengthened support for one viewpoint by exploring different factors relevant to the decision.

In other cases, differences may be resolved by compromise. For example, when discussing food baskets, some participants say food can be prepared in bulk and frozen, but others argue for convenience meals because some people lack time or skills for such preparation. In this instance a compromise is agreed to include a few 
options each week based on pre-prepared food, such as frozen pizza or making a chicken curry with a jar of sauce, with the rest being freshly prepared from raw ingredients. This example shows how people are informed by their own preferences and practices, but recognise that people should have the right to exercise choice about how they buy and prepare food.

Participants also respect diversity in tastes and preferences in other budget areas, and refer to the fact that the definition of the minimum includes a clear reference to having choice. In 2016, pensioners included a bicycle in the list of what a pensioner needs. Some of those making this decision were cyclists, others were not, but they based this decision not on their individual requirements but on what they thought people should be able to choose to do if they wished to.

A final aspect of the consensus-building process is the resolution of an impasse in a previous group. In one instance a group was divided between parents who thought that secondary school children ought to be able to go on school trips outside the UK and those who did not. The former argued that this this was valuable for children, helping them to broaden their horizons; the latter that it was a 'nice to have' rather than a 'need to have' opportunity. A lengthy discussion was not resolved. In a later group, the two arguments were summarised by facilitators and after considering both points of view, participants decided that the need within the terms of the definition was for the child to be able to go on school trips relating to the curriculum, and UKbased trips arranged for the end of the school year, to a theme park, for example. Parents noted that if the family chose to pay for a more expensive international trip this could take the place of the family holiday, so did not require additional resource allocated specifically for this purpose.

\section{Does MIS produce coherent, meaningful results?}

As well as giving qualitative insights into what is required for a socially acceptable living standard, MIS produces quantitative estimates of how many people live below this standard, and how this changes over time, as well as serving as the basis for calculating an accredited 'living wage' (see D'Arcy and Finch, 2016). Consequently it is important for MIS results to be both coherent and consistent in their meaning. In 
particular, where results show change over time, there needs to be confidence that these result from 'real' social change, rather than from arbitrary or incidental fluctuations.

As with any qualitative research, MIS is not intended to produce results that, as with a nationally representative survey, could be replicated within a specified margin of error were it to be repeated with a different set of respondents. However, were results to become overly dependent on who took part and how discussions went within any one wave, its value as a benchmark would be limited.

After a decade during which the research has been conducted a number of times, it is possible to look at the contents of the baskets identified by groups, at the rationales for what is included and at the total value of budgets for each household type, to assess to what extent a consistent pattern emerges. Note that since one objective of MIS is to measure how the minimum is affected by real changes in society, consistency does not mean no change at all, but rather that most significant changes in budgets can be explained by changes in society identified by groups, rather than being subject to unexplained fluctuations in results.

\section{Stability in the contents of baskets}

MIS seeks to ensure that the contents of baskets are not excessively influenced by the views of any one individual or group of individuals, by using the consensusbuilding method described above, and in particular by incorporating iterative stages where decisions from one group are reviewed by others. The research is also designed to address possible discrepancies in how groups go about discussing what is needed through the way in which the tasks undertaken are structured, both within each stage and within the process. In order to have a consistent approach and framing of the task, all group discussions begin with an explanation by the group's facilitators of the MIS 'definition' given above stating that the standard aims to distinguish between 'wants' and 'needs'.

Participants are then asked to imagine walking through the home of the individual under discussion, considering each room in turn to develop a picture of how they would live, in order to reach the living standard described by the definition. The 
shared understanding of how homes are conventionally arranged enables people to visualise the home room by room and think about what kind of activities take place in each space, as well as outside the home in meeting social obligations and leisure requirements. This framework ensures a reasonable consistency of categorisation: items tend to be discussed under similar headings.

This method has produced a high degree of commonality, both in terms of budget lists being drawn up by one group being mainly confirmed by others, and in terms of 'rebase' groups drawing up budgets from scratch. The overall shape of the baskets, and most of the individual items included, has remained the same, underpinned by a high degree of consistency in the rationales identified across groups and across research cycles. Significant changes - such as the introduction of a car for families with children in 2012 and of a laptop and broadband internet access for pensioners in 2014 - have been attributed by groups to changes in society that have been identified in other research. In the first case, a reaction to changes in the level of public transport services (Campaign for Better Transport, 2015) and in the second, the importance and prevalence of internet access (Ofcom, 2016).

The level of similarity over time often extends not only to what is included in broad terms, but also in quite specific details - for example, groups have agreed in each iteration that all households should be able to have a holiday. As with the rest of the budgets, the point is not to generate a prescriptive way in which everyone would take a holiday, but to find a way of describing what kind of holiday would meet people's needs - and this has essentially stayed the same since 2008. All working age budgets include a one week break in self-catering accommodation - for families with children this is on a caravan park, such as a Haven site, near the sea. Working age adults without children talk about a budget for hiring a cottage in the countryside (shared with a friend if single). Pensioners describe a coach tour holiday that includes travel, half-board accommodation, day trips and some evening entertainment. Groups acknowledge that not everyone would choose to have the same kind of holiday, but agree that these descriptions would meet basic needs - a change of scene, a break from routine, a chance to spend time with others. Some groups have discussed the possibility of using the same resources to have a cheap foreign holiday, or a shorter break in a city, but the description they come back to, as 
a way of articulating what components a holiday needs to have, has remained unchanged so far. This kind of stability and consistency over time suggests that the 'answers' being reached each time, independently of what has gone before, are not an arbitrary opinion that would change if the exercise were repeated, but reflect a genuinely shared understanding of what minimum needs are and how to meet them.

This does not mean, however, that all items in a minimum basket remain identical, and various small changes occur that could not readily be explained by changes in society. For example in 2012 parents included six glass tumblers in the kitchen and dining section, whereas in 2016 the list included two sets of four. Another kind of change occasionally occurs because of an alteration in the framework for identifying costs. For example, since 2012, groups have been more systematic than previously in listing specific toiletry and other personal items. Previously, in some cases they had simply estimated the overall cost within certain categories rather than listing each item needed. This appears to have caused an arbitrary increase in the sums specified for personal goods. In the interests of transparency, the MIS facilitators have endeavoured to encourage groups to move to individual costing of items where possible, and this kind of guidance about how to structure budgets should reduce the risk of comparable changes in the way budgets are compiled. However, where this kind of change in approach does occur, it is possible to identify it and estimate the size of its effect when interpreting change over time.

\section{Stability in overall budget levels}

Thus there is bound to be at least some small degree of inconsistency in results from one MIS cycle to the next, which should make users cautious about interpreting small changes. For MIS to be useful, these should not be large, and the results so far suggest that they have not been.

The overall level of consistency in results in quantitative terms is illustrated in Figure 1 , which compares the size and distribution of inflation-adjusted budgets the first and second time that they were researched for single people, six years apart. This period saw a fall in the budget by 2.5 per cent in real terms, a remarkably small change given that the budgets were drawn up by different groups from a blank sheet. The distribution across categories was also very similar overall. The item that fell the 
most was food, due to groups specifying less expenditure on eating out and takeaways, attributed to tougher economic times. Social participation costs also fell, despite computers and the internet being introduced into a minimum basket, because there were budget reductions associated with technological change, including less spent on stationery and newspapers, and the exclusion of a landline from the list of essentials. On the other hand, expenditure on fuel rose, due to a change in the type of housing assumed for people without children. Since the first MIS study in 2008, a model based on social housing (used as a cost baseline, not to argue that everybody is able to access social housing) has been changed to privately rented housing for working age adults without children. MIS groups comprising such adults now consider it so unlikely that a single person without additional needs will be able to rent from a social provider that it is no longer useful even as a baseline. The less thermally efficient nature of the private rented stock compared to social housing explains the increase in the fuel budget. 
Figure 1 Cost of a minimum basket for a single person 2008 and 2014, in 2014 prices*

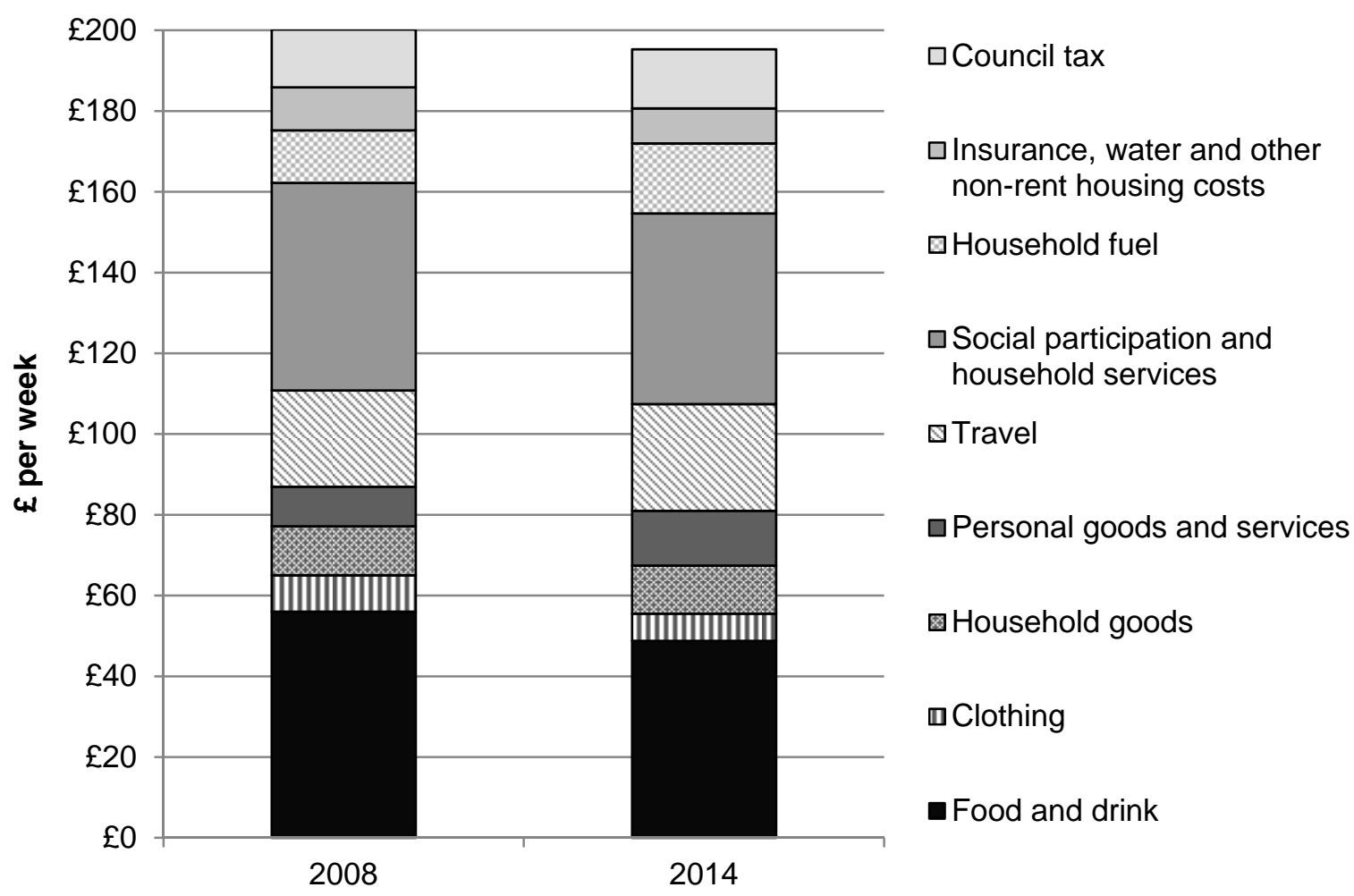

Source: MIS database. *Inflation based on adjusted components of Retail Prices Index, except for clothing, for which average of RPI and CPI used. For explanation of this approach, see Hirsch (2015)

Thus, even the relatively limited differences in the single person's MIS basket in 2008 and 2014 were mainly attributable to explicable changes. Those that are not are small, like the glass tumbler example given above, and to a large extent such small changes in both directions cancel each other out. This has also been the case for families with children and pensioners, although in both cases there have been more explicable changes in the baskets, so picking out what is unexplained can be more complex than in the single person's case shown in Figure 1.

Even when combining changes that can and cannot be explained, the total variation in budgets from 2008 and 2016 was modest, at a time when stagnating general incomes would not lead one to expect a big change in the size of the minimum. Even for families with children, where the need for a car was introduced in 2012 
(Davis et al, 2012), this did not cause a very large increase in the overall household budget requirement for most families, and was offset by some more modest specifications for living in a time of austerity. In real terms, the change in the size of the basket is estimated at between a four per cent fall and a three per cent rise for most families with children. An exception is the case of the lone parent with a baby, for whom the large fixed additional cost of owning a car is high relative to overall expenses, influencing a 12 per cent rise in the value of the basket between 2008 and 2016 (Davis et al, 2016: 30).

In summary, the MIS results have so far been characterised by general stability over time, with some modest changes reflecting changes in society (which is the intention) and some considerably smaller fluctuations that cannot be readily attributed to any 'real' change (which is not the intention). This suggests that as an income benchmark it is far from perfect, but arguably less 'imperfect' than a measure such as relative income, which is not subject to small arbitrary changes in qualitatively derived data, but is also unable to capture specific changes in society that affect costs. For example, the value of a free bus pass is worth nearly 10 per cent of a single pensioner's basket (net of rent and council tax, based on the cost of a bus pass in the non-pensioner budget: author calculation based on MIS data). When the pass first became free for pensioners in 2008, the relative-income benchmark did not change, whereas the MIS budgets excluded the cost of bus travel for pensioners. Further, while MIS accounts for the effect of inflation where it differs significantly between the cost of a minimum basket and the costs faced by an average household (Hirsch et al, 2011), relative income thresholds do not.

\section{Conclusion}

Nine years of MIS research in the UK provides evidence that this approach can give meaningful estimates of minimum household budget requirements, based on social consensus. Building from Townsend's conceptual framework, it recognises the importance of having not only material goods but also those things that constitute and facilitate social participation. The research has also shown that the general public are able to reach a negotiated consensus of what should be included, and to 
articulate a minimum that includes material necessities as well as requirements for participating in society.

The consistency of the findings has been underpinned by the research design, which promotes decisions that are carefully considered, and confirmed by more than one group, based on clearly articulated rationales, to prevent decisions being arbitrary. In practice, this has produced high levels of agreement among multiple members of groups, of corroboration from one group to the next and of consistency across research waves when new participants draw up budgets from scratch. Where significant changes have been identified over time, these are mainly supported by rationales given by members of the public, rooted in lived experience, which point to how life and the social worlds they inhabit are changing. Some smaller unexplained fluctuations remain, so minor changes in budget levels should be interpreted with caution, but it can be argued that more significant ones do reflect 'real' social change.

These characteristics make MIS a useful benchmark in policy, practice and analysis related to low income, especially in combination with other empirical evidence relating to living standards. It can assist policy makers in making grounded judgements about their objectives, particularly in terms of moving households towards income levels at which they can achieve and maintain a reasonable standard of living. In this sense, it is different from a 'poverty line', representing a threshold below which it is unacceptable (in political rhetoric) that people should fall, but rather a beacon of decent living standards for all, marking a direction of travel.

Such a beacon is already directly influencing the setting of wages, through the use of MIS in calculating the pay rate used to accredit Living Wage employers. The Living Wage Commission (2016), which has endorsed this approach, explicitly recognises the value of a standard based on social consensus.

Finally, MIS can be an effective analytical tool for tracking incomes relative to minimum needs, defined with reference to changing social and economic conditions, measured by repeating the research for each household type every four years. Annual reports on how many households fall below the standard use adjusted 
benchmarks that assume that changes noted in each quadrennial research round are spread evenly over four years, helping to avoid a 'lumpy' adjustment of the standard (Padley et al.,, 2017). MIS thus gives form to Townsend's concept of a participatory social minimum, allowing the adequacy of household incomes to be monitored in these terms. 


\section{References}

Atkinson, W. and Deeming, C., 2015, 'Class and cuisine in contemporary Britain: the social space, the space of food and their homology', The Sociological Review, 63: 876-896

Berthoud, Richard and Bryan, M., 201, 'Income, deprivation and poverty - a longitudinal analysis', Journal of Social Policy, Volume 40, Issue 01, pp 135 - 156.

Bourdieu, 1984, Distinction: A Social Critique of the Judgement of Taste, London: Routledge \& Kegan Paul.

Bradshaw, J, (ed.) 1993, Budget Standards for the United Kingdom, Studies in Cash \& Care, Avebury: Aldershot

Bradshaw, J., Middleton. S., Davis, A., Oldfield, N., Smith, N., Cusworth, L. and Williams, J. (2008) A Minimum Income Standard for Britain: What people think. York: Joseph Rowntree Foundation.

Burchardt, T, 2014, Deliberative research as a tool to make value judgements Qualitative Research, 14(3): 353-370. doi: 10.1177/1468794112469624.

Campaign for Better Transport, 2015, Buses in Crisis: A report on bus funding in England and Wales 2010-2016

Daly, M. and Kelly, G, 2015, Families and poverty - everyday life on a low income. Bristol: Policy Press.

D'Arcy, C. and Finch, D, 2016, Calculating a Living Wage for London and the rest of the UK. London: Resolution Foundation.

Davis, A., Hirsch, D and Padley, M, 2012, A Minimum Income Standard for the UK in 2012. York: Joseph Rowntree Foundation.

Davis, A., Hirsch, D and Padley, M, 2014, A Minimum Income Standard for the UK in 2014. York: Joseph Rowntree Foundation.

Davis, A., Hirsch, D and Padley, M, 2016, A Minimum Income Standard for the UK in 2016. York: Joseph Rowntree Foundation.

Davis, A., Hirsch, D., Padley, M. and Marshall, L, 2015, How much is enough? Reaching social consensus on minimum household needs. Loughborough: Centre for Research in Social Policy

Deeming, C, 2010, The historical development of family budget standards in Britain, from the 17th century to the present. Social Policy \& Administration, 44(7), 765-788.

Deeming, C., 2017, Defining Minimum Income (and Living) Standards in Europe: Methodological Issues and Policy Debates, Social Policy and Society, 16(1): 33-48. 
Department for Work and Pensions, 2017, Households Below Average Income: an analysis of the UK income distribution: 1994/5-2015/16. Available at: https://www.gov.uk/government/uploads/system/uploads/attachment_data/file/60009 1/households-below-average-income-1994-1995-2015-2016.pdf [accessed 16 August 2017]

Doyal, L. and Gough, I, 1991, A Theory of Human Need, London: Macmillan.

Fahmy, E, 2014, 'Poverty in Britain, 1999 and 2012: some emerging findings', Journal of Poverty and Social Justice 20(3): pp. 181-91.

Fahmy, E, Pemberton, S. and Sutton, E., 2012, Public Perceptions of Poverty and Social Exclusion: Final Report on Focus Group Findings, working paper No 3, www.poverty.ac.uk

Gordon, D, Adelman, L, Ashworth, K, Bradshaw, J, Levitas, R, Middleton, S, Pantazis, C, Patsios, D, Payne, S, Townsend, P and Williams, J, 2001, Poverty and Social Exclusion in Britain. Bristol: Policy Press/Joseph Rowntree Foundation.

Gordon, D., Mack, J., Lansley, S., Main, G., Nandy, Shailen, Patsios, D. and Pomati, Marco 2013. The impoverishment of the UK. PSE UK first results. Living standards. [Project Report]. Milton Keynes: Open University.

Gordon, D. and C. Pantazis, C 1997, Breadline Britain in the 1990s, Aldershot: Ashgate.

Hick, R., 2012, 'The capability approach: insights for a new poverty focus', Journal of Social Policy, 41, 2, 291-308.

Hill, K., Davis, A., Hirsch, D. and Marshall, L, 2016, Falling Short: the experiences of families living below the Minimum Income Standard. York: Joseph Rowntree Foundation.

Hirsch, D. (2015) A Minimum Income Standard for the UK in 2015 York: Joseph Rowntree Foundation.

Hirsch, D., Padley, M. and Valadez, L., 2016, A Poverty Indicator Based on a Minimum Income Standard. Loughborough: Centre for Research in Social Policy.

Hirsch, D., Perren, K. and Phung, V-H, 2011, Global influences on the cost of a minimum standard of living in the UK. York: Joseph Rowntree Foundation.

Hobson, J.A, 1891, Problems of Poverty: An Inquiry Into the Industrial Condition of the Poor. London: Methuen

Kempson, E, 1996, Life on a low income. York: JRF 
Krueger, R. and Casey, M., 2009, Focus Groups: A Practical Guide for Applied Research, 4th edn, London: Sage.

Kyprianou, L, 2015, Getting by? A year in the life of 30 working families in Liverpool Birmingham: Getting By?

Living Wage Commission, 2016, Closing the gap: A living wage that means families don't go short. London: Living Wage Foundation.

Mack, J. and Lansley, S, 1985, Poor Britain, London: George Allen \& Unwin.

Marmot, M., 2010, Fair Society, Healthy Lives (the Marmot Review), http://www.parliament.uk/documents/fair-society-healthy-lives-full-report.pdf

Merton, Robert K. and Kendall, Patricia L. (1946) "The Focused Interview," American Journal of Sociology 51, no. 6: 541-557.

https://doi.org/10.1086/219886

Middleton, S, 2000, 'Agreeing poverty lines: the development of consensual budget standards methodology', in J. Bradshaw and R. Sainsbury (eds) Researching Poverty, Ashgate: Aldershot, 59-76

Moore, A, 2012, 'Following from the front: theorizing deliberative facilitation', Critical Policy Studies, 6 (2): 146-162.

Morgan, D. L., 1997, Focus Groups as Qualitative Research, 2nd edn, Thousand Oaks, CA and London: Sage.

OFCOM, 2016, Adults' media use and attitudes: Report 2016.

https://www.ofcom.org.uk/_data/assets/pdf_file/0026/80828/2016-adults-mediause-and-attitudes.pdf.

Padley, M., Hirsch, D. and Valadez, L, 2017, Households below a Minimum Income Standard: 2008/09 to 2014/15. York: Joseph Rowntree Foundation.

Parker, H. (ed) 2002, Modest but adequate, York: Family Budget Unit

Ravaillon, M. and Chen, S, 2011, Weakly Relative Poverty, The Review of Economics and Statistics, 93(4): 1251-1261

Rowntree, B.S, 1901, Poverty: a study of town life. London: Macmillan

Sen, A, 1985, Commodities and Capabilities (Amsterdam: North-Holland)

Smith, A, 1776, An enquiry into the nature and causes of the wealth of nations.

Available at http://www.ifaarchive.com/pdf/smith_-

_an_inquiry_into_the_nature_and_causes_of_the_wealth_of_nations\%5B1\%5D.pdf 
Smithson, J. and Diaz, F, 1996, 'Arguing for a collective voice: collaborative strategies in problem-oriented conversation', Text, 16: 251-268.

Storms, B. (2000) 'Wat hebben we nodig om rond te komen? Minimumbudgetten en financiële hulpverlening', Openbaar Centrum voor Maatschappelijk Welzijn-visies, jrg $22,48-53$.

Storms, B., Goedemé, T., Van den Bosch, K. and Devuyst, K, 2013, Towards a Common Framework for Developing Cross-Nationally Comparable Reference Budgets in Europe. Antwerp: Herman Deleeck Centre for Social Policy, University of Antwerp.

Spicker, P, 2012, 'Why refer to poverty as a proportion of median income?' Journal of Poverty and Social Justice 20(2): pp. 163-175.

Townsend, P, 1979, Poverty in the United Kingdom: A Survey of Household Resources and Standards of Living. Harmondsworth: Penguin.

Urfalino, P, 2006, 'Apparent consensus and voting: two modes of collective decision-making', Paper presented at the workshop on The Mechanisms of collective decision-making, Adriano Olivetti Foundation, Rome, April 29, 2006.

Veit-Wilson, J, 1998, Setting adequacy standards. How governments define minimum incomes. Bristol: Policy Press.

Waldegrave, C., Stuart, S. and Stephens, R, 1996, 'Participation in poverty research: drawing on the knowledge of low-income householders to establish an appropriate measure for monitoring social policy impacts', Social Policy Journal of New Zealand, Vol. 7, pp 191-206

Walker, R, 1987, Consensual approaches to the definition of poverty: towards an alternative methodology, Journal of Social Policy 16: 2, 213-226

Winnipeg Harvest and the Social Planning Council of Winnipeg, 2012, A More Inclusive and Generous Canada: The 2012 Acceptable Living Level, 2012, Winnipeg Harvest and the Social Planning Council of Winnipeg http://winnipegharvest.org/wp-content/uploads/2012/02/2012-A.L.L.-REPORT.pdf 